\title{
Adipogenesis Regulation and Endocrine Disruptors: Emerging Insights in Obesity
}

\author{
Jorge Enrique González-Casanova ${ }^{D},{ }^{1}$ Sonia Liliana Pertuz-Cruz, ${ }^{2}$ \\ Nelson Hernando Caicedo-Ortega, ${ }^{3}$ and Diana Marcela Rojas-Gomez $\mathbb{D}^{4}$ \\ ${ }^{1}$ Instituto de Ciencias Biomédicas, Facultad de Ciencias de la Salud, Universidad Autónoma de Chile, Santiago, Chile \\ ${ }^{2}$ Programa de Nutrición y Dietética, Departamento de Nutrición Humana, Facultad de Medicina, \\ Universidad Nacional de Colombia, Bogotá, Colombia \\ ${ }^{3}$ Departamento de Ingeniería Bioquímica, Facultad de Ingeniería, Universidad ICESI, Cali, Colombia \\ ${ }^{4}$ Escuela de Nutrición y Dietética, Facultad de Medicina, Universidad Andres Bello, Santiago, Chile \\ Correspondence should be addressed to Diana Marcela Rojas-Gomez; diana.rojas@unab.cl
}

Received 24 August 2019; Revised 3 December 2019; Accepted 12 December 2019; Published 18 February 2020

Guest Editor: Di Jiang

Copyright @ 2020 Jorge Enrique González-Casanova et al. This is an open access article distributed under the Creative Commons Attribution License, which permits unrestricted use, distribution, and reproduction in any medium, provided the original work is properly cited.

\begin{abstract}
Endocrine disruptors (EDs) are defined as environmental pollutants capable of interfering with the functioning of the hormonal system. They are environmentally distributed as synthetic fertilizers, electronic waste, and several food additives that are part of the food chain. They can be considered as obesogenic compounds since they have the capacity to influence cellular events related to adipose tissue, altering lipid metabolism and adipogenesis processes. This review will present the latest scientific evidence of different EDs such as persistent organic pollutants (POPs), heavy metals, "nonpersistent" phenolic compounds, triclosan, polybrominated diphenyl ethers (PBDEs), and smoke-derived compounds (benzo -alpha-pyrene) and their influence on the differentiation processes towards adipocytes in both in vitro and in vivo models.
\end{abstract}

\section{Introduction}

The prevalence and incidence of overweight and obesity worldwide have increased significantly in the last three decades. According to the World Health Organization (WHO), since 1975 , obesity has nearly tripled, and every year, at least 2.8 million people die as a result of obesity or overweight. By $2016,39 \%$ of adults were overweight, and 13\% were obese; 41 million children under 5 years of age and 340 million children and adolescents between 5 and 19 years of age were overweight or obese [1]. These figures explain the reason why this disease has reached epidemic proportions, and its understanding and intervention are public health priorities.

Diverse studies indicate that the etiology of this chronic disease is multivariate and complex. The predisposing biological factors include genetic characteristics, prenatal determinants, pregnancy, menopause, intestinal microbiota, and viruses. People prone to develop obesity may also be affected by behavioral causes such as excessive energy intake, increased portion sizes, and the practice of a sedentary lifestyle. On the contrary, genetic predisposition to obesity can be influenced by epigenetic triggers such as high availability of food, socioeconomic status, or the presence of chemical contaminants in the environment that could be ingested [2-4].

Due to the deleterious effect of endocrine disruptors on health, it is necessary to characterize the damage by specific dietary exposures of these compounds. This fact implies determining the mechanisms involved in which the food acquires the contaminant. It is also necessary to understand the role as endocrine disruptor and the different physiological and pathological consequences, in particular the relationship with adipogenesis processes.

\section{Adipogenesis}

In living multicellular organisms, certain cell types have the capacity to originate new and specialized cellular lineages, and this characteristic is called cellular differentiation. 
Cellular differentiation is mainly carried out in embryonic development; however, some tissues retain this property of cell differentiation even when the organism is in an adulthood state.

Cell differentiation is activated by a series of signals at the organism level, where these are then translated into specific processes such as differential expression of genes, activation, or inactivation of transcription factors and cellular signaling proteins. The differentiated cell undergoes a series of morphological changes and arrest of cell growth; however, the genetic material of the cell remains unchanged.

Adipogenesis or adipocyte differentiation has been the focus of many studies in recent years. In this process of differentiation, a mesenchymal stem cell (MSC) has the ability to produce mature adipocytes, which are the main constituents of adipose tissue [5, 6].

Adipose tissue was formerly described as a nondynamic tissue whose function was limited to constitute the energy reservoir of the organism, through the accumulation of triglycerides. From the 90 s, this tissue begins to attract the attention of scientists, and it is now considered as a highly active and dynamic tissue with a variety of hormonal, immunological, and regulatory functions of energy homeostasis $[7,8]$. This is one of reasons why the research of adipocyte differentiation process has acquired great importance, and also due to its relationship with different pathologies such as obesity, diabetes mellitus type II (DM type II) [9], insulin resistance [10], osteoporosis [11, 12], rheumatoid arthritis, and osteoarthritis [13]. On the contrary, MSCs are multipotential cells that can give rise to different cell lineages such as osteoblasts, chondrocytes, myocytes, and adipocytes [14].

The process of adipocyte differentiation occurs throughout the different stages of development of organisms and is controlled by both nutritional factors as well as by genetic and environmental factors. There are different models of cell lines that are widely used by researchers $[15,16]$ to study the formation of adipocytes and to understand their relationship with obesity. In vitro models highlight the use of mouse embryonic cell lines 3T3-L1 and 3T3-F442A that can be induced to differentiate into adipocytes under chemical and hormonal exposure.

In response to an extracellular signal, an MSC undergoes processes of proliferation and clonal expansion that originate preadipocytes and high plasticity cells, which can be ultimately differentiated into a cell with a characteristicdefined phenotype, the mature adipocyte. In the first stage of the process, MSC converges into a preadipocyte that does not differ morphologically or phenotypically from its precursor cell, but in which activation processes that involve transcription factors of the AP1 family occur. Subsequently, the terminal differentiation stage is initiated where the resulting adipocyte acquires the specialized equipment for the secretion and synthesis of proteins and lipids specific to the lineage to which it has differentiated [17].

Different signals that influence adipogenesis have been described, for example, fibroblast growth factor type 1 (FGF1) [18] and insulin-like growth factor type 1 (IGF1) [19] are known for their induction action. On the contrary, there is an inhibitory effect on adipogenesis when the WNT signaling [20] or the hedgehog pathway [21] are activated.

\section{Transcription Factors That Regulate Adipogenesis}

It is known that the differentiation of adipocytes is a complex process consisting of several stages, and it is widely regulated by both the specific expression of proteins and transcription factors. In the initial phase, adipogenesis is induced by the expression of binding proteins CCAAT/enhancer $\beta(\mathrm{C} /$ $\mathrm{EBP} \beta$ ) and $\mathrm{C} / \mathrm{EBP} \delta$. The activity of these proteins give rise to a second stage since among their targets are the promoters of the genes that code for peroxisome proliferator-activated receptor gamma $(\operatorname{PPAR} \gamma)$ and $\mathrm{C} / \mathrm{EBP} \alpha$. PPAR $\gamma$ is considered the master transcription factor of the adipocyte differentiation process since when it is activated by binding to its ligand, morphological changes and the expression of all genes specific for mature adipocytes are induced [22].

PPAR $\gamma$ plays an essential role in the process of adipocyte differentiation of white and brown adipose tissue. Two PPAR isoforms have been described, which are produced by alternative splicing. The isoform 2 of PPAR, expressed mainly in adipose tissue and whose function is to promote the storage of triglycerides [23], has been related to obesity, insulin resistance [24], and dyslipidemia [25]. PPAR isoform 1 is ubiquitous in other cell types besides adipocytes. PPAR $\gamma$ activates the promoter of gene coding for $\mathrm{C} / \mathrm{EBP} \alpha$, and reciprocally and inversely, $\mathrm{C} / \mathrm{EBP} \alpha$ activates the $\operatorname{PPAR} \gamma$ promoter, generating a positive feedback loop. Both genes cooperate by binding to sites of promoter regions of various genes that are expressed during the differentiation process, as well as in the mature adipocyte [26]. Some examples of these genes are those that code for proteins involved in insulin sensitivity, lipolysis, and lipogenesis. Krox20 [27] and Kruppel-like factors (KLF) [28] have also been reported in the regulation of differentiation of adipocytes.

\section{Endocrine Disruptors}

Recently, many researchers have focused their interest on socalled EDs or obesogens, bringing attention to their possible etiological incidence of obesity. Both experimental and epidemiological evidence support the idea that low doses of chemical contaminants have endocrine and metabolic effects. Most of these contaminants are present in the food chain and accumulate in the fat mass after absorption $[29,30]$. Secular evidence suggests that some of these EDs may be involved in the global epidemic of obesity, diabetes (diabetogens), as well as in hormone-dependent cancer $[3,4,31]$.

The EDs, are a particular group of well-differentiated chemical compounds, defined as "substances exogenous to the organism that alter the function or functions of the endocrine system, being able to cause adverse effects on the health of an organism, its descendants, in the population in general or in a particular subpopulation" [32]. These substances were initially synthesized to fulfill specific functions, such as the control of pests in agriculture, improve the 
stability of body lotions, or be part of the structure of certain plastics, but with the time, there have been discovered harmful effects derived from continued exposure to them [33].

Among the characteristics of the obesogens is that they are compounds with very different chemical structures capable of acting at shallow doses, show different mechanisms of action, and be able to alter the hormonal balance [34]. They interfere with the body's ability to regulate growth, its development, metabolism, and other functions. There are hundreds of disruptors in the environment, in food, and everyday products. These can contribute to a variety of diseases and disabilities such as obesity, cancer, diabetes, heart disease, reproductive, or neurodevelopmental problems [34].

The Center for Biomedical Research in Network-Physiopathology of Obesity and Nutrition (CIBERobn), which brings 24 Spanish research groups together, has shown that certain synthetic chemical compounds present in the environment and daily life, associated with pesticides and insecticides, but also perfumes, plastics, or cosmetics, predispose to obesity. These chemical compounds, given their effect on fat gain and obesity [34], are also found in synthetic fertilizers, electronic waste, and food additives that are present in the food chain and products of regular consumption such as food, beverages, personal care products, and household cleaning products [35-37].

The possible causality between this group of compounds and the overweight and obesity etiology has been investigated since the increase in the prevalence of obesity. Other metabolic diseases have been associated with the increase in exposure to EDs, as well.

\section{Obesogenic Compounds and Adipogenesis}

As previously mentioned, the obesogenic compounds are heterogeneous and come from various sources (Table 1). So far, there is the characterization of some of those and their effects on the processes of differentiation towards adipocyte [42-44] (Figure 1) (Table 2):

5.1. Persistent Organic Pollutants (POPs). POPs are chemical substances soluble in fats and, therefore, in the organism; they bioaccumulate in fat reserve tissues and biomagnify in the food chain $[33,36]$. The most important route of human exposure to POPs is the consumption of food, especially those of animal origin. Some studies have identified the presence of POPs in oils and fats, meat, eggs, milk, and fish from freshwater ecosystems [38, 80-82].

This phenomenon is explained by its high resistance to chemical degradation and, therefore, its great persistence in the environment and living beings. There is growing epidemiological evidence that frequent exposure to low doses of sure POPs may be related to obesity and metabolic pathologies in the predisposed genetic population. Exposure during early pregnancy to pesticides can lead to the development of obesity in childhood and have been associated with diseases such as diabetes, hypertension, dyslipidemia, and BMI $[33,83]$.
POPs include some pesticides such as dichloro diphenyl trichloroethane (DDT) or hexachlorobenzene (HCB) and some industrial chemicals such as polychlorinated biphenols (PCBs). While the use of these chemicals is prohibited in many countries, their presence persists in the environment due to their high stability, and they are still used in some developing countries [37]. DDT was developed in the 1940s as an insecticide and was also used to combat diseases transmitted by insects, such as malaria. Because DDT has been found to be genotoxic and possibly carcinogenic, its use was banned in the USA in 1972 and the Netherlands in 1973. However, in developing countries, DDT is still used for vector control like malaria [84].

DDT may affect the physiology of adipose tissue. The exposure of DDT in cell cultures has a proadipogenic effect, increasing the expression of PPAR $\gamma$ and the binding of the $\mathrm{C} / \mathrm{EBP} \delta$ protein to DNA during adipogenesis [47]. Studies in the NIH3T3-L1 cell line exposed to the pesticide dichlorodiphenyldichloroethylene (DDE) showed no effect on adipogenesis; however, in the presence of DDT, the mature adipocytes expressed more leptin, resistin, and adiponectin. Similarly, Howell and Howell [45] showed that, in human mesenchymal stem cells (hMSC), DDT could significantly increase the process of differentiation into adipocyte and the molecular markers typical of the fat cell, such as PPAR $\gamma$, leptin, FABP4, and GLUT4 [46]. Additional experimental evidence suggests that the proadipogenic activity of DDT would be through the phosphorylation of the AMPK $\alpha$ protein [48].

5.2. Heavy Metals. In general, many metals have solubility in organic solvents. Human exposure to certain metals such as arsenic, cadmium, and lead has been associated with metabolic alterations such as an increased risk of suffering from DM type II, cardiovascular disease, and obesity. The accumulation of mercury in large fish growing in contaminated water sources, cadmium in cereals and viscera, lead in tubers, or cadmium and arsenic in vegetables have been widely documented [32, 39].

Regarding the influence of heavy metals in the process of adipogenesis, Beier et al. [85] demonstrated through experiments with rats exposed to low concentrations of lead before conception and for 18 months that this heavy metal could stimulate differentiation in mesenchymal cells to mature adipocytes with a concomitant detriment of osteoblastogenesis. This process was further characterized by an inhibition of the cellular signaling pathway of Wnt/ $\beta$-catenin. More recently, the proadipogenic effect of lead was demonstrated in 3T3-L1 cultures, which involved the activation of the ERK, C/EBP $\beta$, and PPAR $\gamma$ pathways [86].

Studies regarding adipogenesis in zebrafish with exposure to cadmium showed a positive association of this metal with the accumulation of adiposity [87].

Regarding arsenic and its role in adipogenesis, there is scientific evidence of its inhibitory influence on adipocyte differentiation. Hou et al. [49] exposed 3T3 L1 cells to this metal and discovered that it is capable of inhibiting 
TABLE 1: Source and route of exposure in human of endocrine disruptors.

\begin{tabular}{|c|c|c|}
\hline Endocrine disruptor & Source and main route of exposure in human & Reference \\
\hline $\begin{array}{l}\text { Persistent organic pollutants: } \\
\text { DDT }\end{array}$ & $\begin{array}{c}\text { Diet (meat, poultry, milk, and fish) and environmental exposition } \\
\text { Used as insecticide for vector control like malaria }\end{array}$ & $\begin{array}{l}\text { Srivastava [38], Wong } \\
\text { and Durrani [36] }\end{array}$ \\
\hline Heavy metals & $\begin{array}{l}\text { Work activity and diet with associated industrial activity (water, food, and } \\
\text { the environment) }\end{array}$ & Ferrer [39] \\
\hline Lead & Large fish growing in contaminated water sources & $\begin{array}{l}\text { Arrebola and Gonzales } \\
\qquad[32]\end{array}$ \\
\hline Cadmium & Cereals and viscera, lead in tubers & $\begin{array}{l}\text { Arrebola and Gonzales } \\
\qquad[32]\end{array}$ \\
\hline Arsenic & Vegetables & $\begin{array}{l}\text { Arrebola and Gonzales } \\
\qquad[32]\end{array}$ \\
\hline $\begin{array}{l}\text { "Nonpersistent" phenolic } \\
\text { compounds BPA, TBBPA }\end{array}$ & $\begin{array}{l}\text { Linings of canisters, specific plastic containers, thermal printing papers, } \\
\text { dental composite fillings, medical devices, polycarbonate, plastic resins and } \\
\text { materials used in food containers } \\
\text { Inhalation or ingestion of dust; by food intake like fish, milk, eggs, meat, } \\
\text { meat products, and breast milk }\end{array}$ & $\begin{array}{l}\text { Fénichel and Chevalier } \\
\qquad[29]\end{array}$ \\
\hline Phthalates & $\begin{array}{l}\text { Used as plasticizers } \\
\text { Dispersants, lubricants, emulsifying agents, perfumes and nail polishes } \\
\text { Comes from foods that have absorbed the compound from their packaging } \\
\text { or the manufacturing process } \\
\text { Particulate matter in the air, water, or skin contact with plastics that contain } \\
\text { it; plastic food containers may also contain DEHP } \\
\text { Water from sources of discharge that have had contact with polymers }\end{array}$ & $\begin{array}{l}\text { Mezcua et al. [33] } \\
\text { Azeredo et al. [40] }\end{array}$ \\
\hline Triclosan & $\begin{array}{c}\text { Used as antibacterial agent } \\
\text { Antibacterial soaps, toothpaste, toothbrushes, dental rinses, laundry } \\
\text { detergents, kitchen cutting boards and plastics in furniture, toys, and } \\
\text { sporting goods }\end{array}$ & Wong and Durrani [36] \\
\hline PBDEs & $\begin{array}{l}\text { Used as effective flame retardants in plastics, electronics, automobiles, } \\
\text { homes, furniture, textiles, and construction materials } \\
\text { Butter, fish, and other foods, as well as other foods that contain animal fats }\end{array}$ & Mezcua et al. [33] \\
\hline Benzo-alpha-pyrene & $\begin{array}{l}\text { Foods cooked on the grill or the barbecue; smoked, roasted or fried at high } \\
\text { temperatures foods; oils subjected to repeated heating }\end{array}$ & $\begin{array}{l}\text { Arrebola and Gonzales } \\
\qquad[32] \\
\text { Franco-Tobón and } \\
\text { Ramírez Botero [41] }\end{array}$ \\
\hline
\end{tabular}

TABLE 2: Effect of endocrine disruptor on adipogenesis.

\begin{tabular}{|c|c|c|c|}
\hline $\begin{array}{l}\text { Endocrine disruptor (chemical } \\
\text { structure) }\end{array}$ & Experimental model & Biological effect & Reference \\
\hline \multicolumn{4}{|l|}{ Persistent organic pollutants } \\
\hline & $\begin{array}{l}\text { NIH3T3-L1 cells } \\
\text { Human mesenchymal } \\
\text { cells }\end{array}$ & $\begin{array}{c}\text { Proadipogenic effect } \\
\text { Proadipogenic effect, increased } \\
\text { expression of PPAR } \gamma \text {, leptin, FABP4, } \\
\text { and GLUT4 }\end{array}$ & $\begin{array}{l}\text { Howell and Mangum [45] } \\
\text { Strong et al. [46] }\end{array}$ \\
\hline dichlorodiphenyltrichloroethane & 3T3 L1 cell culture & $\begin{array}{l}\text { Proadipogenic effect, increased } \\
\text { expression of PPAR } \gamma \text {, and the } \\
\text { binding of C/EBP } \delta \text { protein to DNA, } \\
\text { increased phosphorylation of the } \\
\text { AMPK } \alpha \text { protein }\end{array}$ & $\begin{array}{l}\text { Moreno-Aliaga and Matsumura } \\
\text { [47], Kim et al. [48] }\end{array}$ \\
\hline \multicolumn{4}{|l|}{ Heavy metals } \\
\hline Lead & $\begin{array}{l}\text { Mesenchymal cells from } \\
\text { pregnant rat }\end{array}$ & $\begin{array}{l}\text { Proadipogenic effect, decreased } \\
\text { osteoblastogenesis } \\
\text { Activation of the ERK pathway and } \\
\text { expression of C/EBP } \beta \text { and PPAR } \gamma\end{array}$ & Hou et al. [49] \\
\hline Cadmium & Zebrafish & Accumulation of adiposity. & Beezhold et al. [50] \\
\hline
\end{tabular}


TABle 2: Continued.

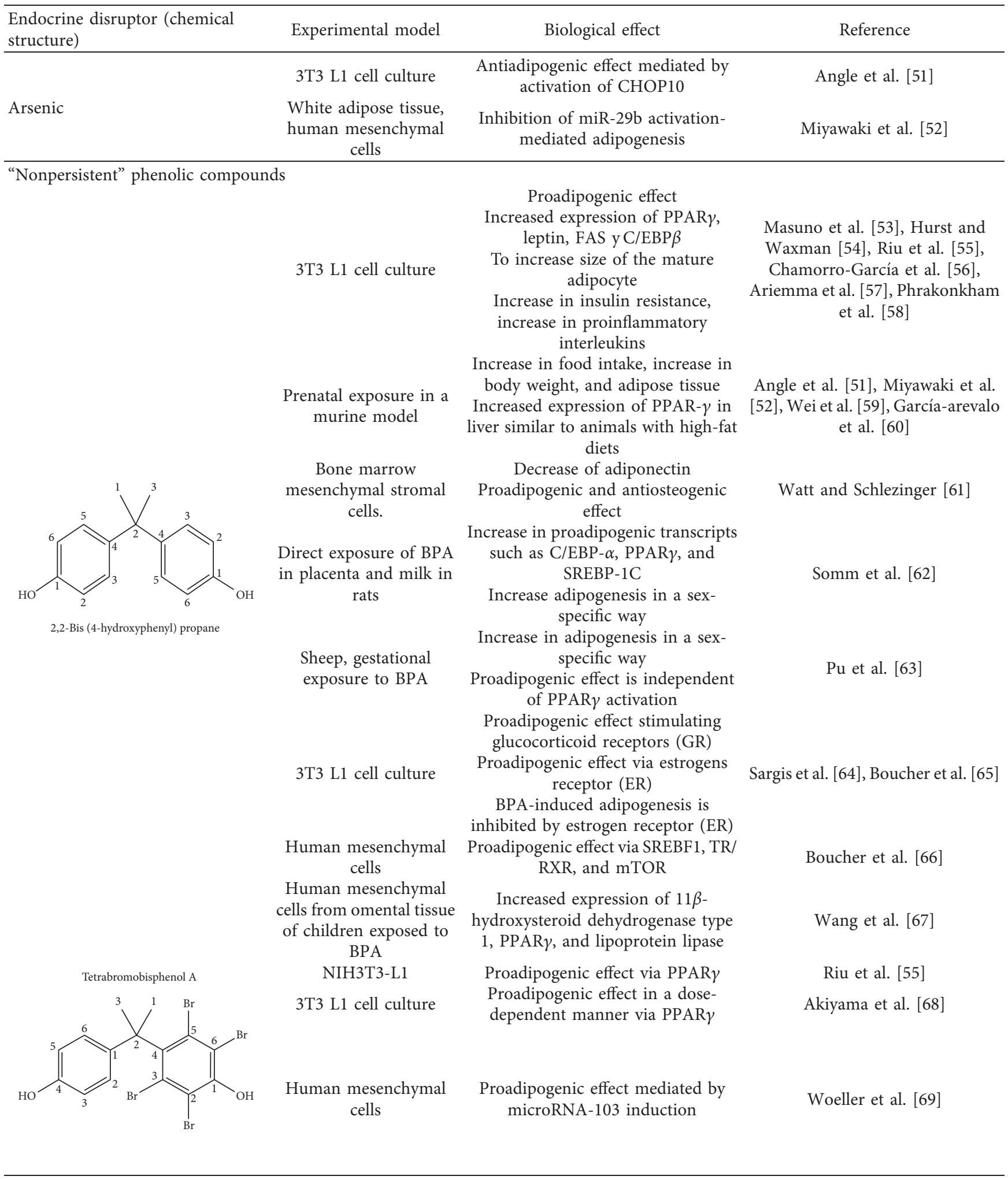


TABle 2: Continued.

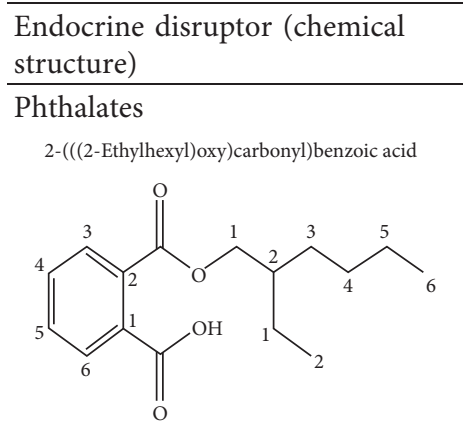
Experimental model

3T3 L1 cell culture

COS- 1 cell culture

Fetal exposure in mice

Human mesenchymal

cells
Biological effect

Proadipogenic effect via PPAR $\gamma$

Activation of PPAR $\gamma, \operatorname{PPAR} \alpha$

Increase in weight and fat mass in the offspring

Increase expression of transcripts related to the PPAR $\gamma$ signaling pathway

Increase expression of genes involved with lipid metabolism<smiles>CCCCOC(=O)c1ccccc1C(=O)OCc1ccccc1</smiles>

Bone marrow stromal cells

3T3 L1 cell culture

Mouse mesenchymal cell lines $\mathrm{C} 3 \mathrm{H} 10 \mathrm{~T} 1 / 2$. Decreased differentiation towards
osteoblasts, and an increase in adipogenesis vía PPAR $\gamma$

Proadipogenic effect via PPAR $\gamma$ Proadipogenic effect
Feige et al. [70], Bility et al. [71], Hao et al. [72]

Hurst and Waxman [54]

Hao et al. [72]

Ellero-Simatos et al. [73]

\section{Reference}

Epigenetic effect on histones of the PPAR $\gamma$ promoter

Chiu et al. [74]

Yin et al. [75]

2-Dicyanomethylene-1,1,3,4,5,5-hexacyanopentene<smiles>N#CC(C#N)=C(C#N)C(C#N)C(C#N)C(C#N)C#N</smiles>

3T3 L1 cell culture

Proadipogenic effect via glucocorticoid receptor (GR)
Sargis et al. [64]
Triclosan<smiles>Oc1cc(Cl)ccc1Oc1ccc(Cl)cc1Cl</smiles>

Human mesenchymal cells
Antiadipogenic effect

Decrease of adiponectin and lipoprotein lipase
Sonkar et al. [76]

PBDEs<smiles>Brc1ccc(Oc2ccc(Br)cc2)cc1</smiles>

polybrominated diphenyl ether<smiles>Cc1ccc(Oc2ccc(Br)cc2)cc1</smiles>

3T3 L1 cell culture
Guo et al. [77] 
TABLE 2: Continued.

\begin{tabular}{l} 
Endocrine disruptor (chemical Biological effect \\
structure) \\
\hline Benzo-alpha-pyrene
\end{tabular}

adipogenesis through the activation of CHOP10, an inhibitory molecule for the transcriptional activity of $\mathrm{C} / \mathrm{EBP} \beta$, thus causing the suppression of adipogenesis. CHOP10 is a protein that increases its expression in response to the stress of the endoplasmic reticulum produced by the incorrect folding of proteins. Similarly, Beezhold et al. [50] showed that arsenic can increase the expression of microRNA, miR$29 \mathrm{~b}$, involved in the regulation of the cell cycle and in the increase in the expression of cyclin D1, which results in inhibition of the differentiation towards the fat cell.

5.3. Other "Nonpersistent" Phenolic Compounds. Denotes a wide variety of chemical compounds used in industrial applications, with the main characteristic that they suffer a relatively rapid degradation and/or excretion in the body. In spite of this, constant exposure provokes the continual presence of them in biological samples of the general population [32]. Within this group, it is possible to find the bisphenol A (BPA).

BPA is a "nonpersistent" phenolic compound widely used in the manufacture of polycarbonate plastics and epoxy resins. It is present in the linings of canisters, specific plastic containers, thermal printing papers, dental composite fillings, medical devices, polycarbonate, plastic resins, and materials used in food containers among others. It is highly elastic and resistant to heat material [29]. It has been shown that BPA can migrate from food containers and contaminate them, so these can be an important source of exposure to this compound.

The majority of the population is exposed to BPA daily, and there is currently an unprecedented controversy regarding its possible metabolic disruptor effect since experimental studies have shown that exposure to BPA induces an increase in weight in mice, as well as a high risk of DM type II [32]. Through experiments with rats, it has been demonstrated that relatively low doses of BPA- equivalent to daily and frequent exposure levels in large part of the population-act in a similar way to estradiol, the most potent form of estrogen that, among other aspects, influences the distribution of body fat in women. Exposure to these compounds at inadequate levels and certain stages of development-especially in the fetal stage and childhood-exerts a significant influence on both obesity and the development of diabetes [34]. Several epidemiological studies have found that high urinary concentrations of BPA in adults and children were associated with obesity and increased waist circumference [36].

BPA is a compound that has also been widely studied regarding its effect on lipid metabolism and cellular processes of adipocyte differentiation. It has been associated that a high intake of BPA together with a high-fat/highsucrose diet leads to similar changes in the structure of the intestinal microbial community in mice [35]. Studies in humans have shown that prenatal exposure to BPA is associated with an increase in body fat at 7 years of age or an increase in body mass index at 9 years of age [36]. Regarding the effect of prenatal exposure to BPA, it has been shown that in experimental models with animals, there is an increase in food consumption, body weight, adipose tissue, and decrease in adiponectin concentrations $[51,52,59]$. These results support the hypothesis that exposure to BPA in critical states of adipose tissue development may alter the homeostasis of the adipocyte, thus increasing the risk of developing complications related to obesity [88].

Regarding the influence of BPA on adipogenesis, several studies have shown this correlation. Using cell models of the 3T3-L1 line exposed to BPA, it was observed that the process of adipogenesis is exacerbated $[53-55,89]$. In this same line of evidence, ChamorroGarcía et al. [56] stimulated 3T3 L1 cells with different concentrations of $\mathrm{BPA}$, and at $10 \mathrm{nM}$, adipogenesis was stimulated. At $100 \mathrm{nM}$, a significant increase in triglyceride accumulation was observed. Chronic exposure to BPA in cultures of 3T3-L1 preadipocytes for three weeks at concentrations of $1 \mathrm{nM}$ increased the proliferation of preadipocytes and produced hypertrophic adipocytes with impaired insulin signal, reducing glucose utilization and increasing the production of proinflammatory interleukins [57].

The target molecule of BPA's action that would play a significant role in this process is not fully elucidated yet; 
however, some research groups would bet on the master regulator of adipogenesis: PPAR $\gamma$. Phrakonkham et al. [58] demonstrated that concentrations of $80 \mu \mathrm{M}$ BPA are capable of activating PPAR $\gamma$ and adipocyte-specific proteins such as leptin, FAS, and $\mathrm{C} / \mathrm{EBP} \beta$. Exposure of BPA in prenatal conditions can increase the expression of PPAR- $\gamma$ in the liver when compared with the control group or with animals fed high-fat diets [60]. Watt and Schlezinger [61] demonstrated a proadipogenic and antiosteogenic effect in mesenchymal stromal cells of bone marrow through the activation of this transcription factor.

Studies aimed to evaluate the adipogenesis in vivo demonstrated that direct exposure of BPA in rats through placenta and milk increases adipogenesis in a sex-specific manner since they observed an increase in proadipogenic transcripts such as PPAR $\gamma, \mathrm{C} / \mathrm{EBP}-\alpha$, and sterol regulatory element-binding factor 1 (SREBF-1) [62]. In studies with sheep, gestational exposure to BPA overregulates the expression of PPAR $\gamma$ in females; however, in male sheep, it reduced the expression of PPAR $\gamma$, showing that the effect of BPA can be sex-specific [63].

Additional studies have attempted to show that BPA alters the processes of adipogenic differentiation in a manner independent of the regulation of PPAR $\gamma$. Experiments by Chamorro-García et al. [56] show that BPA alone is capable of activating adipogenesis in 3T3 L1 cells; however, it fails to stimulate differentiation in stromal cells. When using PPAR $\gamma$ antagonists in the $3 \mathrm{~T} 3 \mathrm{~L} 1$ cultures, no effect was observed, concluding that the proadipogenic effect of BPA is independent of PPAR $\gamma$. Sargis et al. [64] showed through luciferase assays in cultures of 3T3 L1 that BPA may possess intrinsic glucocorticoid-like activity, promoting adipogenesis through potentiation of the glucocorticoid receptor (GR) activity.

Studies on the mechanism of BPA in adipogenesis in preadipocytes of donors with healthy BMI showed induction of adipogenesis in the absence of exogenous glucocorticoids. Estradiol had no positive effect on differentiation, but BPAinduced adipogenesis was inhibited by estrogen receptor (ER) antagonists, but not by GR antagonists, suggesting that BPA acts through a nonclassical ER pathway [65].

Microarray assays performed on human subcutaneous preadipocytes cultures exposed to BPA demonstrated that the pathways involved in promoting adipogenesis would be via SREBF1, the TR/RXR receptor, and the mTOR pathway [66].

Wang et al. [67] analyzed the effect of BPA on omental adipose tissues of children during adipogenesis and observed an increase in the expression of $11 \beta$-hydroxysteroid dehydrogenase type 1 , an enzyme that catalyzes the conversion of cortisone to cortisol, which is a glucocorticoid proadipogenic. It also observed an increase in PPAR- $\gamma$ and lipoprotein lipase.

Regarding tetrabromobisphenol-A (TBBPA), the brominated analogue of BPA, Riu et al. [55] studied the effect of this compound on cell differentiation towards adipocytes in the NIH3T3-L1 cell line and determined that TBBPA presents specific binding with the protein $\operatorname{PPAR} \gamma$, activating it, which ultimately favored the accumulation of triglycerides in the cell. Similar results were also obtained in the studies of Akiyama et al. [68], who first demonstrated the presence of TBBPA in human milk, but also determined the proadipogenic activity of TBBAP and its brominated derivatives in $3 \mathrm{~T} 3-\mathrm{L} 1$ cells.

To understand how TBBPA has a regulatory effect on the process of differentiation towards adipocyte, Woeller et al. [69] propose a mechanism in which TBBPA reduces Thy 1 levels, which results in the stimulation of adipogenesis through the induction of microRNA-103.

5.4. Phthalates. With regard to phthalates, these compounds are poorly biodegradable and highly bioaccumulable in the food chain [33]. They are mainly used as plasticizers and, therefore, are present in a large number of everyday objects, such as plastic food containers and medical devices, including tubes for parenteral feeding [32]. They are also found in dispersants, lubricants, emulsifying agents, perfumes, and nail polishes. It has been established that the highest exposure to phthalates comes from foods that have absorbed the compound from their packaging or the manufacturing process $[33,40]$. Due to their solubility, they are concentrated in fatty foods such as dairy products, high-fat meat, mayonnaise, fat, fish, and shellfish [30]. Phthalates form noncovalent interactions and can easily leach into the environment. This property, combined with its widespread use in consumer products, allows exposure to these chemicals in the US population [36]. Exposure to high levels of phthalates has been associated with alterations in thyroid hormone levels, insulin resistance, increased risk of obesity or low fertility, and increase in BMI and waist circumference $[32,38]$. This phenomenon is explained because ingested phthalates cause dysregulation of glucose metabolism, insulin resistance, and adipogenesis [35]. Phthalates are metabolized by the body and metabolites are usually excreted in the urine [45].

Phthalate metabolites have been shown to activate PPAR receptors and have antiandrogenic effects that may contribute to the development of obesity. Prenatal exposure of mice to phthalate DEHP led to an increase in body weight, as well as an increase in body fat in male offspring. Similar findings were reported in different studies with different animal models [37].

Regarding phthalates and their effect on adipogenesis, it has been shown that (mono-(2-ethylhexyl) phthalate) $(\mathrm{MEPH})$ favors the formation of adipocytes through the activation of PPAR $\gamma[70,71]$. Hao et al. [72, 90] demonstrated that this proadipogenic effect was dose-dependent; however, uterus exposure of mice significantly increased weight and fat mass in the offspring, possibly indicating an effect of MEHP on adipogenesis in alive mice.

Ellero-Simatos et al. [73] tested the obesogenic effect of MEHP, by stimulating cultures of human preadipocyte cells during adipogenesis. This research group also carried out metabonomic analyzes with the nuclear magnetic resonance (1H NMR) technique and transcriptome analysis. The results of these experiments showed that MEHP could increase the 


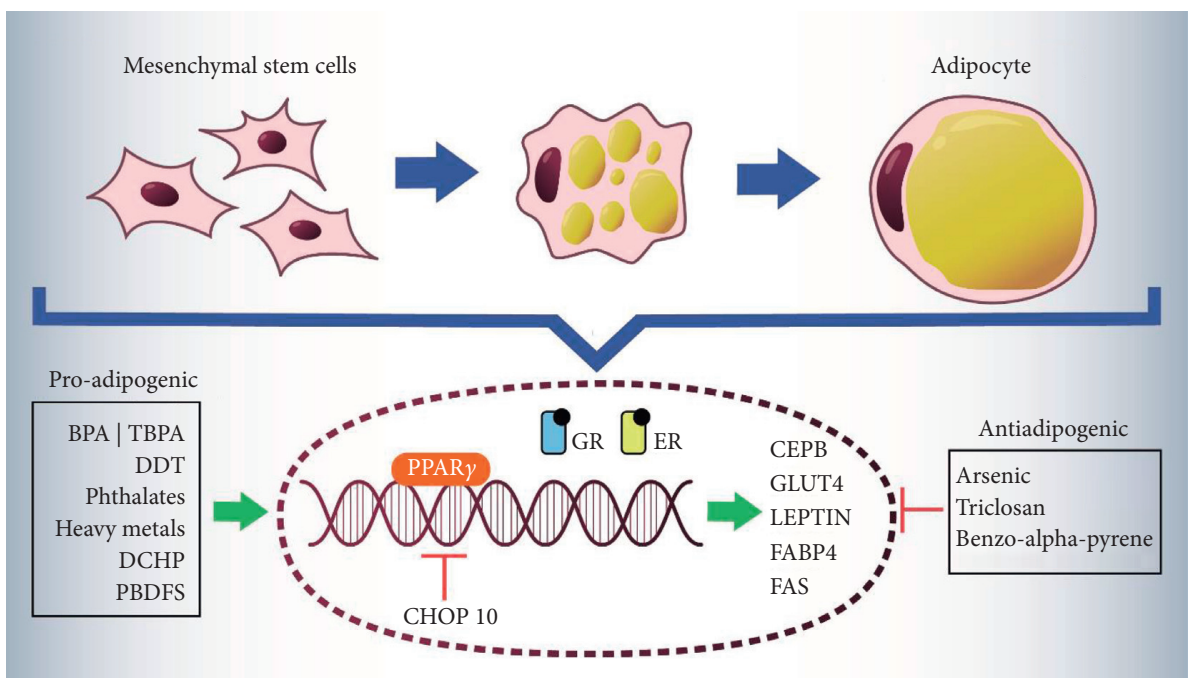

FIGURE 1: Schematic representation of effects of endocrine disruptors on adipogenic differentiation.

expression of at least 12 transcripts related to the PPAR $\gamma$ signaling pathway, in addition to increasing the expression of genes involved with lipid metabolism: glyceroneogenesis, cytosolic phosphoenolpyruvate carboxykinase, as well as reduction in the release of fatty acids.

Additionally, phthalates have also been related to an alteration in osteoblast homeostasis and adipogenesis in the bone marrow. Studies of Chiu et al. [74], in cell cultures of bone marrow stromal cells exposed to different concentrations of MEHP, showed a decrease in differentiation towards osteoblasts and a concomitant increase in adipogenesis.

Benzyl butyl phthalate (BBP) has also been related to a proadipogenic activity, activating PPAR $\gamma$, favoring the accumulation of lipids in a dose-dependent manner, and also producing an alteration of lipid metabolism, glyceroneogenesis, and fatty acid synthesis in 3T3-L1 cell cultures [75]. The Sonkar group [76] confirmed the proadipogenic role of BBP, but also suggested a model where BBP produces epigenetic alterations involving the increase of lysine 9 of histone 3 (H3K9), which is typically increased in the promoter of PPAR $\gamma$ in mature adipocyte, which was accompanied by an alteration in histone methylation/acetylation due to the presence of BBP in mouse mesenchymal cell lines $\mathrm{C} 3 \mathrm{H} 10 \mathrm{~T} 1 / 2$.

Additionally, Sargis et al. [64] investigated the role of dicyclohexyl phthalate (DCHP) during the process of adipogenesis in 3T3-L1 and discovered that this compound is a glucocorticoid receptor activator, which is a critical regulator in the differentiation towards adipocyte. Based on this result, the group suggests that DCHP could have a proadipogenic effect through a synergistic effect with other adipogenic cell signals.

5.5. Triclosan. It is a widely used antibacterial agent commonly found in antibacterial soaps, toothpaste, toothbrushes, dental rinses, laundry detergents, kitchen cutting boards, and plastics in furniture, toys, and sporting goods. In 2016, the
Food and Drug Administration (FDA) issued rules prohibiting the use of triclosan in hand and body antibacterial products, citing the lack of evidence to support its effectiveness as an antiseptic. So far, the disruptive endocrine effects of triclosan are not well understood. Some studies have shown effects on the endocrine system of animals. Studies in animals show that high levels of triclosan interfere with estrogen, androgen, and thyroid hormone. Children who are exposed to triclosan may also be more likely to develop allergic hyperreactivity [36]. Concerning its influence on adipocyte differentiation, it has been shown that triclosan has an inhibitory effect of adipogenesis in a model with hMSCs, and this antiadipogenic effect was concentration-dependent, decreasing the production of typical markers of the cell fat, such as adiponectin and lipoprotein lipase [77].

5.6. Compounds Derived from Smoke (Benzo-Alpha-Pyrene). It is a polycyclic aromatic hydrocarbon compound and a potent carcinogen, which originates in combustion processes and is present in foods cooked on the grill or the barbecue $[32,41]$. No obesogenic effect has yet been associated; however, an antiadipogenic effect has been demonstrated in cell cultures of human preadipocytes, and this effect is mediated through a specific receptor, the aryl-hydrocarbon receptor (AHR) [79].

5.7. Polybrominated Diphenyl Ethers (PBDEs). They are a class industrialized chemicals widely used in the manufacturing processes of many materials and currently used as effective flame retardants in plastics, electronics, automobiles, homes, furniture, textiles, and construction materials. Different studies have discovered the connection between PBDE and food, which informs about the presence of PBDEs in butter, fish, and other foods, as well as other foods that contain animal fats [33].

Pentabrominated diphenyl ether is increasing in the tissues and body fluids of individuals in the USA and can be detected in blood, breast milk, and urine samples from 
Americans. Diphenyl ether has generally been eliminated in the USA and banned in the European Union. The PBDEs can accumulate in white adipose tissue and are highly lipophilic. These persistent compounds can be released into the blood, especially during weight loss. They have a structure similar to thyroid hormone, and some studies have found that exposure to these can alter the hormonal balance of the thyroid [36]. They have also been implicated in having a proadipogenic effect in 3T3-L1 cell cultures, increasing the accumulation of lipids and the expression of $\mathrm{C} / \mathrm{EBP} \alpha, \operatorname{PPAR} \gamma$ during the differentiation process [78].

\section{Conclusion}

Adipogenesis is a highly controlled process and is regulated by physiological and environmental conditions. Humans are constantly and chronically exposed to a variety of endocrine disruptors, some with obesogenic activity, which act at shallow doses and showing different mechanisms of action altering the hormonal balance. The exposure to the obesogens can happen continuously during the different stages of development, and in this context, the perinatal exhibition is relevant because the effects can be permanent in the organism.

Endocrine disruptors can alter lipid metabolism, promote fat accumulation, and interfere with processes such as adipogenesis. There is sufficient evidence in models with cell lines, human mesenchymal cells and in rodents that demonstrate that obesogens can have targets of action key molecules of the process of differentiation towards adipocyte, such as molecules that regulate the initial stages of differentiation, $\mathrm{C} / \mathrm{BP} \beta$ and $\mathrm{C} / \mathrm{EBP} \delta$, or secondary stage proteins such as $\operatorname{PPAR} \gamma$.

There are diverse compounds-originally from foodthat are associated with possible obesogenic effects; however, there is no enough scientific evidence to prove such association. However, it is necessary to understand in more detail the complexity of the mechanisms involved in the differentiation of fat cells and the influence of EDs in the adipogenesis and the etiology of obesity.

\section{Conflicts of Interest}

The authors declare that they have no conflicts of interest.

\section{References}

[1] World Health Organization (WHO), Obesity and Overweight, WHO, Geneva, Switzerlandhttp://www.who.int/news-room/ fact-sheets/detail/obesity-and-overweight.

[2] H. C. Kadauh and A. Acosta, "Current paradigms in the etiology of obesity," Techniques in Gastrointestinal Endoscopy, vol. 19, no. 1, 2016.

[3] P. F. Baillie-Hamilton, "Chemical toxins: a hypothesis to explain the global obesity epidemic," The Journal of Alternative and Complementary Medicine, vol. 8, no. 2, pp. 185192, 2002.

[4] R. R. Newbold, E. Padilla-Banks, W. N. Jefferson, and J. J. Heindel, "Effects of endocrine disruptors on obesity," International Journal of Andrology, vol. 31, no. 2, pp. 201-208, 2008.
[5] M. V. Heindel, Z. Jiang, M. Du, and G. J. Hausman, "Adipogenesis: it is not just lipid that comprises adipose tissue," Journal of Genomics, vol. 1, pp. 1-4, 2013.

[6] P. J. Havel, "Update on adipocyte hormones: regulation of energy balance and carbohydrate/lipid metabolism," Diabetes, vol. 53, no. 1, pp. S143-S151.

[7] E. E. Kershaw and J. S. Flier, "Adipose tissue as an endocrine organ," The Journal of Clinical Endocrinology \& Metabolism, vol. 89, no. 6, pp. 2548-2556, 2004.

[8] H. S. Camp, D. Ren, and T. Leff, "Adipogenesis and fat-cell function in obesity and diabetes," Trends in Molecular Medicine, vol. 8, no. 9, pp. 442-447, 2002.

[9] B. Gustafson, S. Hedjazifar, S. Gogg, A. Hammarstedt, and U. Smith, "Insulin resistance and impaired adipogenesis," Trends in Endocrinology \& Metabolism, vol. 26, no. 4, pp. 193-200, 2015.

[10] N. Nahum, E. Forti, O. Aksanov, and R. Birk, "Insulin regulates Bbs4 during adipogenesis," IUBMB Life, vol. 69, no. 7, pp. 489-499, 2017.

[11] G. Birk, G. Brunetti, M. F. Faienza et al., "Osteoporosis and obesity: role of Wnt pathway in human and murine models," World Journal of Orthopedics, vol. 5, no. 3, pp. 242-246, 2014.

[12] C. J. Rosen and M. L. Bouxsein, "Mechanisms of disease: is osteoporosis the obesity of bone?" Nature Clinical Practice Rheumatology, vol. 2, no. 1, pp. 35-43, 2006.

[13] J. Dragojevič, D. B. Logar, R. Komadina et al., "Osteoblastogenesis and adipogenesis are higher in osteoarthritic than in osteoporotic bone tissue," Archives of Medical Research, vol. 42, no. 5, pp. 392-397, 2011.

[14] N. Beyer Nardi and L. da Silva Meirelles, "Mesenchymal stem cells: isolation, in vitro expansion and characterization," Handbook of Experimental Pharmacology, vol. 174, pp. 249282, Springer, Berlin, Germany, 2011.

[15] F. Ruiz-Ojeda, A. Rupérez, C. Gomez-Llorente, A. Gil, and C. Aguilera, "Cell models and their application for studying adipogenic differentiation in relation to obesity: a review," International Journal of Molecular Sciences, vol. 17, no. 7, p. 1040, 2016.

[16] S. P. Poulos, M. V. Dodson, and G. J. Hausman, "Cell line models for differentiation: preadipocytes and adipocytes," Experimental Biology and Medicine, vol. 235, no. 10, pp. 1185-1193, 2010.

[17] G. J. Hausman, M. V. Dodson, K. Ajuwon et al., "BOARDINVITED review: the biology and regulation of preadipocytes and adipocytes in meat animals 1, 2," Journal of Animal Science, vol. 87, no. 4, pp. 1218-1246, 2009.

[18] C. H. Widberg, F. S. Newell, A. W. Bachmann et al., "Fibroblast growth factor receptor 1 is a key regulator of early adipogenic events in human preadipocytes," American Journal of Physiology-Endocrinology and Metabolism, vol. 296, no. 1, pp. E121-E131, 2009.

[19] M. Kawai and C. J. Rosen, "The IGF-I regulatory system and its impact on skeletal and energy homeostasis," Journal of Cellular Biochemistry, vol. 111, no. 1, pp. 14-19, 2010.

[20] C. Christodoulides, C. Lagathu, J. K. Sethi, and A. Vidal-Puig, "Adipogenesis and WNT signaling," Trends in Endocrinology \& Metabolism, vol. 20, no. 1, pp. 16-24, 2009.

[21] J. A. Pospisilik, D. Schramek, H. Schnidar et al., "Drosophila genome-wide obesity screen reveals hedgehog as a determinant of brown versus white adipose cell fate," Cell, vol. 140, no. 1, pp. 148-160, 2010.

[22] P. Tontonoz and B. M. Spiegelman, "Fat and beyond: the diverse biology of PPAR $\gamma$," Annual Review of Biochemistry, vol. 77, no. 1, pp. 289-312, 2008. 
[23] E. Mueller, "Understanding the variegation of fat: novel regulators of adipocyte differentiation and fat tissue biology," Biochimica et Biophysica Acta (BBA)-Molecular Basis of Disease, vol. 1842, no. 3, pp. 352-357, 2014.

[24] N. Saraf, P. K. Sharma, S. C. Mondal, V. K. Garg, and A. K. Singh, "Role of PPARg2 transcription factor in thiazolidinedione-induced insulin sensitization," Journal of Pharmacy and Pharmacology, vol. 64, no. 2, pp. 161-171, 2012.

[25] V. C. Kaippert, S. K. Uehara, C. L. D’Andrea et al., "Influence of the body mass and visceral adiposity on glucose metabolism in obese women with Pro12Pro genotype in PPARgamma2 gene," Nutrición Hospitalaria, vol. 28, no. 3, pp. 694-700, 2013.

[26] M. I. Lefterova, Y. Zhang, D. J. Steger et al., "PPAR and C/EBP factors orchestrate adipocyte biology via adjacent binding on a genome-wide scale," Genes \& Development, vol. 22, no. 21, pp. 2941-2952, 2008.

[27] Z. Chen, J. I. Torrens, A. Anand, B. M. Spiegelman, and J. M. Friedman, "Krox20 stimulates adipogenesis via C/EBP $\beta$ dependent and -independent mechanisms," Cell Metabolism, vol. 1, no. 2, pp. 93-106, 2005.

[28] Y. Oishi, I. Manabe, K. Tobe et al., "Krüppel-like transcription factor KLF5 is a key regulator of adipocyte differentiation," Cell Metabolism, vol. 1, no. 1, pp. 27-39, 2005.

[29] P. Fénichel and N. Chevalier, "Environmental endocrine disruptors: new diabetogens?" Comptes Rendus Biologies, vol. 340, no. 9-10, pp. 446-452, 2017.

[30] K. Tordjman, L. Grinshpan, L. Novack et al., "Exposure to endocrine disrupting chemicals among residents of a rural vegetarian/vegan community," Environment International, vol. 97, pp. 68-75, 2016.

[31] F. Arvelo, F. Sojo, and C. Cotte, "Contamination, endocrine disruptors and cancer," Investigación Clinica, vol. 57, no. 1, pp. 77-92, 2016.

[32] J. Arrebola and B. Gonzales, "Exposición a contaminantes ambientales por vía alimentaria y repercusiones metabólicas relacionadas con la obesidad," Nut Clin Med, vol. X, pp. 164-174, 2016.

[33] M. Mezcua, M. A. Martínez-Uroz, M. M. Gómez-Ramos, M. J. Gómez, J. M. Navas, and A. R. Fernández-Alba, "Analysis of synthetic endocrine-disrupting chemicals in food: a review," Talanta, vol. 100, pp. 90-106, 2012.

[34] A. Doadrio, "Role of obesogens in adipogenicity and obesity," An Real Acad Farm, pp. 206-214, 2016.

[35] G. Velmurugan, T. Ramprasath, M. Gilles et al., "Gut microbiota, endocrine- disrupting chemicals, and the diabetes epidemic," Trends Endocrinol Metab, vol. 28, no. 8, pp. 612625, 2017.

[36] K. H. Wong and T. S. Durrani, "Exposures to endocrine disrupting chemicals in consumer products-a guide for pediatricians," Current Problems in Pediatric and Adolescent Health Care, vol. 47, no. 5, pp. 107-118, 2017.

[37] J. J. Heindel, B. Blumberg, M. Cave et al., "Metabolism disrupting chemicals and metabolic disorders," Reproductive Toxicology, vol. 68, pp. 3-33, 2017.

[38] V. Srivastava, T. Srivastava, and M. S. Kumar, "Fate of the persistent organic pollutant (POP)Hexachlorocyclohexane $(\mathrm{HCH})$ and remediation challenges," International Biodeterioration \& Biodegradation, vol. 140, pp. 43-56, 2019.

[39] A. Ferrer, "Metal poisoning," Anales del Sistema Sanitario de Navarra, vol. 26, no. 1, pp. 141-153, 2003.

[40] D. G. d. Azeredo, V. L. Gass, J. F. B. Milanez, and A. C. Pizzato, "Evidências em relação aos riscos à saúde pelo uso do plástico em embalagens alimentícias," Ciência \& Saúde, vol. 10, no. 3, pp. 184-191, 2017.

[41] Y. N. Franco Tobón and C. M. Ramírez Botero, "Benzo[a] pyrene from food and cancer," Perspect Nut Hum, vol. 15, pp. 99-112, 2013.

[42] M. E. Bateman, A. L. Strong, J. A. McLachlan, M. E. Burow, and B. A. Bunnell, "The effects of endocrine disruptors on adipogenesis and osteogenesis in mesenchymal stem cells: a review," Frontiers in Endocrinology, vol. 7, no. 7, p. 171, 2017.

[43] J. J. Heindel, R. Newbold, and T. T. Schug, "Endocrine disruptors and obesity," Nature Reviews Endocrinology, vol. 11, no. 11, pp. 653-661, 2015.

[44] J. E. González-Casanova, S. L. P. Cruz, M. C. Vivas et al., "Influence of Endocrine disrupting chemicals on adipogénesis," Arch Venez Farmacol Rer, vol. 37, no. 1, pp. 164-172, 2018.

[45] G. Howell III and L. Mangum, "Exposure to bioaccumulative organochlorine compounds alters adipogenesis, fatty acid uptake, and adipokine production in NIH3T3-L1 cells," Toxicology in Vitro, vol. 25, no. 1, pp. 394-402, 2011.

[46] A. L. Strong, Z. Shi, M. J. Strong et al., "Effects of the endocrine-disrupting chemical DDT on self-renewal and differentiation of human mesenchymal stem cells," Environmental Health Perspectives, vol. 123, no. 1, pp. 42-48, 2015.

[47] M. J. Moreno-Aliaga and F. Matsumura, "Effects of 1,1,1trichloro-2,2-bis(p-chlorophenyl)-ethane ( $\mathrm{p}, \mathrm{p}^{\prime}$-DDT) on 3T3-L1 and 3T3-F442A adipocyte differentiation," Biochemical Pharmacology, vol. 63, no. 5, pp. 997-1007, 2002.

[48] J. Kim, Q. Sun, Y. Yue et al., “4,4'-Dichlorodiphenyltrichloroethane (DDT) and 4, $4^{\prime}$-dichlorodiphenyldichloroethylene (DDE) promote adipogenesis in 3T3-L1 adipocyte cell culture," Pesticide Biochemistry and Physiology, vol. 131, pp. 40-45, 2016.

[49] Y. Hou, P. Xue, C. G. Woods et al., "Association between arsenic suppression of adipogenesis and induction of CHOP10 via the endoplasmic reticulum stress response," Environmental Health Perspectives, vol. 121, no. 2, pp. 237243, 2013.

[50] K. Beezhold, L. R. Klei, and A. Barchowsky, "Regulation of cyclin D1 by arsenic and microRNA inhibits adipogenesis," Toxicology Letters, vol. 265, pp. 147-155, 2017.

[51] B. M. Angle, R. P. Do, D. Ponzi et al., "Metabolic disruption in male mice due to fetal exposure to low but not high doses of bisphenol A (BPA): evidence for effects on body weight, food intake, adipocytes, leptin, adiponectin, insulin and glucose regulation," Reproductive Toxicology, vol. 42, pp. 256-268, 2013.

[52] J. Miyawaki, K. Sakayama, H. Kato, H. Yamamoto, and H. Masuno, "Perinatal and postnatal exposure to bisphenol a increases adipose tissue mass and serum cholesterol level in mice," Journal of Atherosclerosis and Thrombosis, vol. 14, no. 5, pp. 245-252, 2007.

[53] H. Masuno, T. Kidani, K. Sekiya et al., "Bisphenol a in combination with insulin can accelerate the conversion of 3T3-L1 fibroblasts to adipocytes," Journal of Lipid Research, vol. 43, pp. 676-684, 2002.

[54] C. H. Hurst and D. J. Waxman, "Activation of PPAR and PPAR by environmental phthalate monoesters," Toxicological Sciences, vol. 74, no. 2, pp. 297-308, 2003.

[55] A. Riu, M. Grimaldi, A. le Maire et al., "Peroxisome proliferator-activated receptor $\gamma$ is a target for halogenated analogs of bisphenol A," Environmental Health Perspectives, vol. 119, no. 9, pp. 1227-1232, 2011. 
[56] R. Chamorro-García, S. Kirchner, X. Li et al., "Bisphenol A diglycidyl ether induces adipogenic differentiation of multipotent stromal stem cells through a peroxisome proliferatoractivated receptor gamma-independent mechanism," Environmental Health Perspectives, vol. 120, no. 7, pp. 984-989, 2012.

[57] F. Ariemma, V. D’Esposito, D. Liguoro et al., "Low-dose bisphenol-a impairs adipogenesis and generates dysfunctional 3T3-L1 adipocytes," PLoS One, vol. 11, no. 3, Article ID e0150762, 2016.

[58] P. Phrakonkham, S. Viengchareun, C. Belloir, M. Lombès, Y. Artur, and M.-C. Canivenc-Lavier, "Dietary xenoestrogens differentially impair 3T3-L1 preadipocyte differentiation and persistently affect leptin synthesis," The Journal of Steroid Biochemistry and Molecular Biology, vol. 110, no. 1-2, pp. 95-103, 2008.

[59] J. Wei, Y. Lin, Y. Li et al., "Perinatal exposure to bisphenol A at reference dose predisposes offspring to metabolic syndrome in adult rats on a high-fat diet," Endocrinology, vol. 152, no. 8, pp. 3049-3061, 2011.

[60] M. García-Arevalo, P. Alonso-Magdalena, J. Rebelo Dos Santos et al., "Exposure tobisphenol-a during pregnancy partially mimics the effects of a high-fat diet altering glucose homeostasis and gene expression in adult male mice," PLoS One, vol. 9, no. 6, Article ID e100214, 2014.

[61] J. Watt and J. J. Schlezinger, "Structurally-diverse, PPAR $\gamma$ activating environmental toxicants induce adipogenesis and suppress osteogenesis in bone marrow mesenchymal stromal cells," Toxicology, vol. 331, pp. 66-77, 2015.

[62] E. Somm, V. M. Schwitzgebel, A. Toulotte et al., "Perinatal exposure to bisphenol a alters early adipogenesis in the rat," Environmental Health Perspectives, vol. 117, no. 10, pp. 1549-1555, 2009.

[63] Y. Pu, J. D. Gingrich, J. P. Steibel, and A. Veiga-Lopez, "SexSpecific Modulation of Fetal Adipogenesis by Gestational Bisphenol A and Bisphenol S Exposure," Endocrinology, vol. 158, no. 11, pp. 3844-3858, 2017.

[64] R. M. Sargis, D. N. Johnson, R. A. Choudhury, and M. J. Brady, "Environmental endocrine disruptors promote adipogenesis in the 3T3-L1 cell line through glucocorticoid receptor activation," Obesity, vol. 18, no. 7, pp. 1283-1288, 2010.

[65] J. G. Boucher, A. Boudreau, and E. Atlas, "Bisphenol A induces differentiation of human preadipocytes in the absence of glucocorticoid and is inhibited by an estrogen-receptor antagonist," Nutrition \& Diabetes, vol. 4, no. 1, p. e102, 2014.

[66] J. G. Boucher, M. Husain, A. Rowan-Carroll, A. Williams, C. L. Yauk, and E. Atlas, "Identification of mechanisms of action of bisphenol a-induced human preadipocyte differentiation by transcriptional profiling," Obesity, vol. 22, no. 11, pp. 2333-2343, 2014.

[67] J. Wang, B. Sun, M. Hou, X. Pan, and X. Li, "The environmental obesogen bisphenol A promotes adipogenesis by increasing the amount of $11 \beta$-hydroxysteroid dehydrogenase type 1 in the adipose tissue of children," International Journal of Obesity, vol. 37, no. 7, pp. 999-1005, 2013.

[68] E. Akiyama, H. Kakutani, T. Nakao et al., "Facilitation of adipocyte differentiation of 3T3-L1 cells by debrominated tetrabromobisphenol a compounds detected in Japanese breast milk," Environmental Research, vol. 140, pp. 157-164, 2015.

[69] C. F. Woeller, E. L. Flores, S. J. Pollock, and R. P. Phipps, "Editor's highlight: Thy1 (CD90) expression is reduced by the environmental chemical tetrabromobisphenol-A to promote adipogenesis through induction of microRNA-103," Toxicological Sciences, vol. 157, no. 2, pp. 305-319, 2017.

[70] J. N. Feige, L. Gelman, D. Rossi et al., "The endocrine disruptor monoethyl-hexyl-phthalate is a selective peroxisome proliferator-activated receptor $\gamma$ modulator that promotes adipogenesis," Journal of Biological Chemistry, vol. 282, no. 26, pp. 19152-19166, 2007.

[71] M. T. Bility, J. T. Thompson, R. H. McKee et al., “Activation of mouse and human peroxisome proliferator-activated receptors (PPARs) by phthalate monoesters," Toxicological Sciences, vol. 82, no. 1, pp. 170-182, 2004.

[72] C. Hao, X. Cheng, H. Xia et al., "The endocrine disruptor mono-(2-ethylhexyl) phthalate promotes adipocyte differentiation and induces obesity in mice," Bioscience Reports, vol. 32, no. 6, pp. 619-629, 2013.

[73] S. Ellero-Simatos, S. P. Claus, C. Benelli et al., "Combined transcriptomic-1H NMR metabonomic study reveals that monoethylhexyl phthalate stimulates adipogenesis and glyceroneogenesis in human adipocytes," Journal of Proteome Research, vol. 10, no. 12, pp. 5493-5502, 2011.

[74] C.-Y. Chiu, S.-C. Sun, C.-K. Chiang et al., "Plasticizer di(2ethylhexyl)phthalate interferes with osteoblastogenesis and adipogenesis in a mouse model," Journal of Orthopaedic Research, vol. 36, no. 4, pp. 1124-1134, 2018.

[75] L. Yin, K. S. Yu, K. Lu, and X. Yu, "Benzyl butyl phthalate promotes adipogenesis in 3T3-L1 preadipocytes: a high content cellomics and metabolomic analysis," Toxicology in Vitro, vol. 32, pp. 297-309, 2016.

[76] R. Sonkar, C. A. Powell, and M. Choudhury, "Benzyl butyl phthalate induces epigenetic stress to enhance adipogenesis in mesenchymal stem cells," Molecular and Cellular Endocrinology, vol. 431, pp. 109-122, 2016.

[77] L.-W. Guo, Q. Wu, B. Green et al., "Cytotoxicity and inhibitory effects of low-concentration triclosan on adipogenic differentiation of human mesenchymal stem cells," Toxicology and Applied Pharmacology, vol. 262, no. 2, pp. 117-123, 2012.

[78] E. W. Y. Tung, A. Boudreau, M. G. Wade, and E. Atlas, "Induction of adipocyte differentiation by polybrominated diphenyl ethers (PBDEs) in 3T3-L1 cells," PLoS One, vol. 9, no. 4, Article ID e94583, 2014.

[79] N. Podechard, O. Fardel, M. Corolleur, M. Bernard, and V. Lecureur, "Inhibition of human mesenchymal stem cellderived adipogenesis by the environmental contaminant benzo(a)pyrene," Toxicology in Vitro, vol. 23, no. 6, pp. 1139-1144, 2009.

[80] P. D. Darbre, "Endocrine disruptors and obesity," Current Obesity Reports, vol. 6, no. 1, pp. 18-27, 2017.

[81] W. Guo, B. Pan, S. Sakkiah et al., "Persistent organic pollutants in food: contamination sources, health effects and detection methods," International Journal of Environmental Research and Public Health, vol. 8, no. 22, p. 16, 2019.

[82] J. S. Bedi, V. Singh, A. Gupta, J. P. S. Gill, and R. S. Aulakh, "Persistent organic pollutants (POPs) in fresh water farm fish species from Punjab (India) and evaluation of their dietary intake for human risk assessment," Human and Ecological Risk Assessment: An International Journal, vol. 24, no. 6, pp. 1659-1672, 2018.

[83] E. E. Hatch, J. W. Nelson, R. W. Stahlhut, and T. F. Webster, "Association of endocrine disruptors and obesity: perspectives from epidemiological studies," International Journal of Andrology, vol. 33, no. 2, pp. 324-332, 2010.

[84] M. D. Cock and M. van de Bor, "Obesogenic effects of endocrine disruptors, what do we know from animal and human studies?" Environment International, vol. 70, pp. 15-24, 2014. 
[85] E. E. Beier, J. R. Maher, T.-J. Sheu et al., "Heavy metal lead exposure, osteoporotic-like phenotype in an animal model, and depression of Wnt signaling," Environmental Health Perspectives, vol. 121, no. 1, pp. 97-104, 2013.

[86] C. N. Martini, M. Gabrielli, G. Bonifacino, M. M. Codesido, and M. d. C. Vila, "Lead enhancement of 3T3-L1 fibroblasts differentiation to adipocytes involves ERK, C/EBP $\beta$ and PPAR $\gamma$ activation," Molecular and Cellular Biochemistry, vol. 437, no. 1-2, pp. 37-44, 2018.

[87] A. J. Green, C. Hoyo, C. J. Mattingly et al., "Cadmium exposure increases the risk of juvenile obesity: a human and zebrafish comparative study," International Journal of Obesity, vol. 42, no. 7, pp. 1285-1295, 2018.

[88] A. E.-S. Shafei, E. S. Nabih, K. A. Shehata et al., "Prenatal exposure to endocrine disruptors and reprogramming of adipogenesis: an early-life risk factor for childhood obesity," Childhood Obesity, vol. 14, no. 1, pp. 18-25, 2018.

[89] H. C. Nunes, W. R. Scarano, E. Deffune, S. L. Felisbino, I. Porreca, and F. K. Delella, "Bisphenol a and mesenchymal stem cells: recent insights," Life Sciences, vol. 206, pp. 22-28, 2018.

[90] C. Hao, X. Cheng, H. Xia et al., "Erratum: the endocrine disruptor mono-(2-ethylhexyl) phthalate promotes adipocyte differentiation and induces obesity in mice," Bioscience Reports, vol. 33, no. 1, p. 185, 2013. 